\title{
Author Correction: Cancer in wildlife: patterns of emergence
}

Patricia A. Pesavento, Dalen Agnew, Michael K. Keel and Kevin D. Woolard

Nature Reviews Cancer (2018) https://doi.org/10.1038/s41568-018-0045-0

Published online 16 August 2018

In the originally published article, the aetiology of the single case of B cell lymphoma found in the Mountain gorilla was incorrectly referred to as Gibbon lymphocryptovirus 1 in Table 1. The correct aetiology is Gbb lymphocryptovirus 1. This has now been corrected in all versions of the original article.

https://doi.org/10.1038/s41568-019-0113-0 I Published online 31 January 2019 